http://sciforum.net/conference/ece-1

Conference Proceedings Paper - Energies ,, Whither Energy Conversion? Present Trends, Current Problems and Realistic Future Solutions"

\title{
Biofuel Similar to Biodiesel Obtained by Using a Lipase from Rhizopus Oryzae, Optimized by Response Surface Methodology
}

Carlos Luna $^{1, *}$, Cristobal Verdugo ${ }^{2}$, Enrique D. Sancho ${ }^{3}$, Diego Luna ${ }^{1,4}$, Juan Calero ${ }^{1}$, Alejandro Posadillo ${ }^{4}$, Felipa M. Bautista ${ }^{1}$, Antonio A. Romero ${ }^{1}$

1 Department of Organic Chemistry, University of Cordoba, Campus de Rabanales, Ed. Marie Curie,14014, Córdoba, Spain; E-Mail: qo2luduc@uco.es (C.L.); qo1lumad@uco.es (D.L.); p72camaj@uco.es (J.C.); qo1baruf@uco.es (F.M.B.), qo1rorea@uco.es (A.A.R.)

2 Crystallographic Studies Laboratory, Andalusian Institute of Earth Sciences, CSIC, Avda. Las Palmeras, n4, 18100, Armilla, Granada, Spain; E-Mail: cverdugoe@ lec.csic.es (C.V.)

3 Department of Microbiology, University of Córdoba, Campus de Rabanales, Ed. Severo Ochoa, 14014, Córdoba, Spain; E-Mail: edsancho@uco.es (E.D.S.)

4 Seneca Green Catalyst S.L., Campus de Rabanales, 14014, Córdoba, Spain; E-Mail: seneca@uco.es (A.P.)

* Author to whom correspondence should be addressed; E-Mail: qo2luduc@uco.es (C.L.); Tel.: +34-957-212-065; Fax: +341-957-212-066.

Received: 22 December 2013 /Accepted:10 February 2014 / Published: 14 March 2014

Abstract: A new biofuel like biodiesel applicable to diesel engines is obtained by the enzymatic ethanolysis reaction of sunflower oil with ethanol, in free solvent media, by using BIOLIPASE- ${ }^{\circledR}$, a low cost powdered enzyme preparation containing obtained lipases from a strain of Rhizopus oryzae. This is a multipurpose additive from Biocon®Spain, used in food industry. This biofuel integrates glycerol as monoglyceride (MG) together to two fatty acid ethyl esters (FAEE) molecules by the application of the 1,3selective lipases. Thus, this process minimizes waste generation and maximizes efficiency of the process because no residual glycerol is produced. Response surface methodology (RSM) is employed to evaluate the main reaction parameters (reaction temperature, oil/ethanol ratio and $\mathrm{pH}$ environment) on the conversion of sunflower oil. Water content and amount of lipase were also investigated. Regarding the results, we found that it operates optimally with a water content of the reaction medium of $0.15 \%, 0.05-0.1 \%$ lipase by weight relative to the weight of oil used, $20{ }^{\circ} \mathrm{C}$, volume ratio $(\mathrm{ml} / \mathrm{ml})$ oil/ethanol 
12/3.5 and $\mathrm{pH} 12$ (by addition of $50 \mu \mathrm{l}$ of $10 \mathrm{~N} \mathrm{NaOH}$ dissolution). These achieved results have proven a very good efficiency of the biocatalyst in the studied selective process.

Keywords: biodiesel; Rhizopus oryzae lipase (ROL); BIOLIPASE-R ${ }^{\circledR}$; selective transesterification; ethanolysis; ecodiesel; sunflower oil; glycerol.

\section{Introduction}

The production of biodiesel has become very important in recent years as potential alternative to partially satisfy the future energetic demands in the transport sector [1-3]. Since, the availability of the fossil fuel, from the last century until nowadays the main primary source of energy, is becoming increasingly more limited, so it is also more accepted and assumed that the cheap and easily accessible fossil fuel era is coming to its end. Thus, in the short term seems be essential to obtain new technical processes to replace current fossil fuels by renewable raw material, in an economically and environmentally viable alternative.

In this respect, among the different existing methods to produce biofuels, better than microemulsions and emulsifications, even direct use of triglycerides, transesterification with short chain alcohols is currently the most attractive and widely accepted methodology for biodiesel production [4]. This usually involves the use of homogeneous base catalysts operating under mild conditions. In order to shift the equilibrium to the production of fatty acid methyl esters (FAME), an excess of methanol is normally utilized in the process to produce biodiesel and always glycerol is obtained as main byproduct through the stepwise process. Thus, besides to the alkaline impurities that need to be removed in the conventional method, the accumulation of glycerol is the main drawback of this method, not only because it supposes a lowering in the atomic yield of the process, but also because obtained biodiesel need to be compulsory cleaned of this residual glycerol, to avoid problems of polymerization and of course of performance in DI motors. In this way, several consecutive water washing steps are generally applied, where it is actually spent a lot of water to get the complete glycerol elimination [5].

To stay away from the associated problems with the glycerol generation in the conventional process, a series of alternative methods are being under investigation. They all are based on achieving various glycerol derivatives, in the same transesterification process. So, it is avoided the compulsory, complex and expensive additional separation process of glycerol. In this way, not only it is prevented the waste generation but also it is increased the process yield. These novel methodologies are able to prepare methyl esters of fatty acids from lipids, using different acyl acceptors, instead of methanol, in the transesterification process, which directly afford alternative glycerol derivatives co-products [6]. Thus, the transesterification reaction of triglycerides with dimethyl carbonate (DMC) [7], ethyl acetate [8] or methyl acetate [9] can generate a mixture of three molecules of FAME or FAEE and one of glycerol carbonate (GC) or glycerol triacetate (triacetin). Thus, the atom efficiency is also improved because the total number of atoms involved in the reaction is part of the final mixture. These mixtures, including the glycerol derivative molecules, have relevant physicochemical properties to be employed as biodiesel-like biofuel [10] in conventional DI motors. 
In this way, our research group have recently developed a protocol for the preparation of a new biodiesel-like biofuel, that integrates glycerol into their composition via 1,3-regiospecific enzymatic transesterification of sunflower oil using free [11-14] and immobilized [11,14,15] porcine pancreatic lipase (PPL). It was found that operating conditions of such enzymatic process, compared to the conventional biodiesel preparation method, were much smoother and without generation of any acidic or alkaline impurities. Thus, the named Ecodiesel biofuel [11-15], synthesized through the partial ethanolysis of triglycerides with 1,3-selective lipases, is constituted by a mixture of two parts of FAEE and one of MG. These MGs integrate the glycerol as a derivative product that is soluble in the FAEE mixture, thus working as a biodiesel-like a biofuel. In the current case, it is used ethanol as a cheap reagent, instead of the more expensive ones such as dimethyl carbonate or methyl acetate. This procedure takes advantage of the 1,3 selective nature of the most known lipases, which allows to "stop" the process in the second step of the alcoholysis, thereby obtaining the previously commented mixture of two moles of FAEE and one of MG as products, Fig.1. In this way, the glycerol remains in the form of monoglycerides, which avoids the production of glycerol as by-product, reducing the environmental impact of the process.

Figure 1. Representative scheme of Ecodiesel production by application of 1,3 selective enzymatic catalysis. A biofuel with similar physicochemical properties to the conventional biodiesel is obtained, avoiding glycerol generation as byproduct.

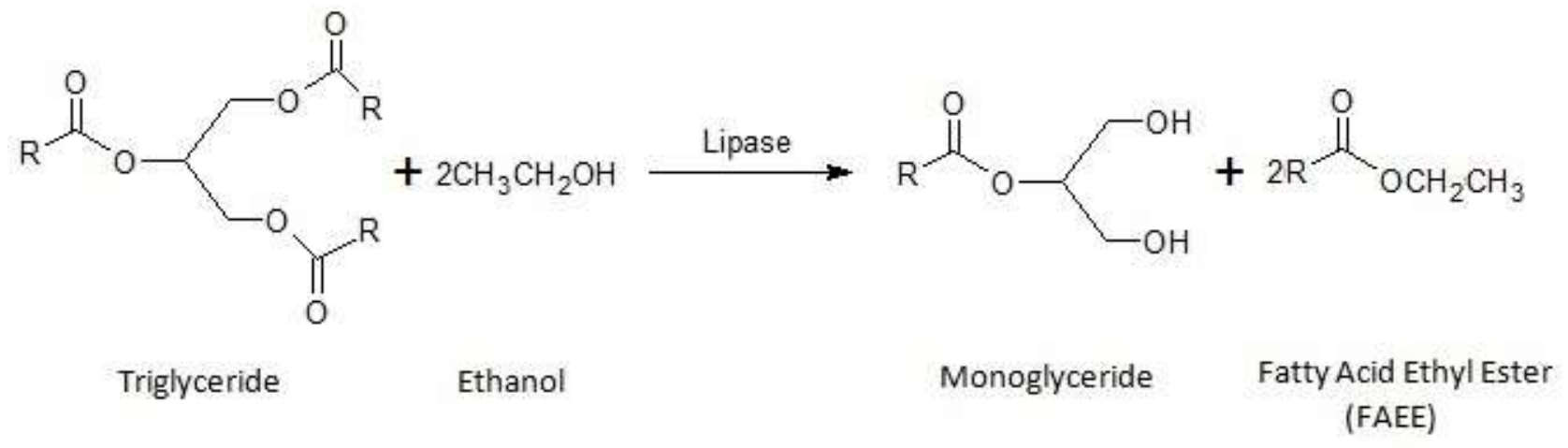

In summary, the enzymatic process to obtain this new biofuel operates under much smoother conditions, besides impurities are no produced and the biofuel produced exhibits similar physicochemical properties to those of conventional biodiesel. Last, but not least, monoacylglycerides (MG) enhance biodiesel lubricity, as it was demonstrated by recent studies [16-18]. Moreover, the ethanol that is not spent in the enzymatic process remains also in the reaction mixture in such a way that, the products blend obtained after the reaction can be directly used as a fuel. In this respect, current studies [19-21] have proven that blends of diesel fuel and ethanol with biodiesel produces some little less in maximum power output than regular diesel. No significant difference in the emissions of $\mathrm{CO}_{2}$, $\mathrm{CO}$, and NOx between regular diesel and biodiesel, ethanol and diesel blends was observed. But the use of these blends resulted in a reduction of particulate matter. Consequently, such blends can be used in a diesel engine without any modification taking into account the limited changes obtained respect to 
the use of pure diesel. Thus, the Ecodiesel expression is being currently ascribed to whichever blend of fatty acid alkyl ester with ethanol, alone or with any proportion of diesel fuel $[21,22]$.

The current existing limitations to apply industrial lipases have been mainly associated with their high production costs, which can be overcome through the application of molecular technologies to achieve the production of purified enzymes in sufficiently high quantities. In this way, to achieve the economic viability, the crucial factors affecting productivity of enzymatic biodiesel synthesis are the suitable raw materials and the selected lipase. The latter can be properly modified to improve stability and catalytic efficiency, by optimization of parameters molar substrates ratio, temperature, water activity and $\mathrm{pH}$ of enzyme's microenvironment [23]. In this respect, although Ecodiesel was initially achieved using pig pancreatic lipases (PPL), remarkable results have been also obtained with a low cost purified microbial lipase, Lipopan 50 BG (Novozymes AS, Denmark) [12], from Thermomyces lanuginosus microorganism, usually used as bread emulsifier (bread improver) [24]. The application of an available lipase on an industrial scale is a significant approximation to get an economically feasible biofuel production by enzymatic method.

In this context of researches targeted to improve the viability and competitiveness of the enzymatic process, the present study aims to evaluate the BIOLIPASE- $\mathrm{R}^{\circledR}$, a low cost powdered enzyme preparation containing obtained lipases from a strain of Rhizopus oryzae (ROL). This is a multipurpose additive from Biocon ${ }^{\circledR}-$ Spain, used in food industry. Although the Rhizopus oryzae lipase has been described in the synthesis of conventional biodiesel as well as in other transesterification processes [25], under our best knowledge, BIOLIPASE-R® never has been used in any fine chemical process, including oil transesterification. Thus, we try to put in value the 1,3 selective behaviour of this low cost, industrial commercial lipase, to make feasible the profitable production of alternative biofuels, using an enzymatic approach. In this respect, in order to evaluate the influence of several crucial reaction parameters in the transesterification reaction, optimum values of water content and amount of lipase were firstly determined. After that, it is applied with these optimum values a multi-factorial design of experiments and response surface methodology for other reaction parameters such as temperature, oil/ethanol volumetric ratio and $\mathrm{pH}$ environments, achieved by adding different quantities of aqueous solutions of $\mathrm{NaOH} 10 \mathrm{~N}$, to optimize the catalytic behaviour of this 1,3-selective ROL constituting BIOLIPASE- ${ }^{\circledR}$. In the current partial ethanolysis of sunflower oil, it is obtained a biofuel that integrates glycerol as MG, together to the different FAEEs obtained in the enzymatic ethanolysis process, as well as the excess of unreacted ethanol. This biofuel mixture currently named Ecodiesel is able to directly operate diesel engines, alone or in whichever mixture with diesel fuel, without anymore separation or purification.

\section{Results and Discussion}

\subsection{Comparative chromatograms of standardized reaction products.}

To identify the most characteristic components of biofuels obtained by enzymatic alcoholysis, as well as to compare their rheological properties, were used several commercial standards of reference for FAME, FAEE, MG and TG, as it is shown in Fig. 2. Here it is also included a representative sample of monoglycerides of sunflower oil, that was easily achieved by the substitution of methanol or 
ethanol by glycerol, in a conventional alcoholysis process with $\mathrm{KOH}$ as homogeneous catalyst following standard experimental conditions.

Figure 2. Superimposed chromatograms of sunflower oil (black), as well as obtained chromatograms in the alcoholysis of sunflower oil with methanol (FAME), ethanol (FAEE) and glycerol (monoglycerides, MG) corresponding to blue, pink and red respectively. Selectivity is defined as the percentage of reaction products with retention times $(\mathrm{RT} \leq 25)$ similar to those hydrocarbons that compose the diesel.

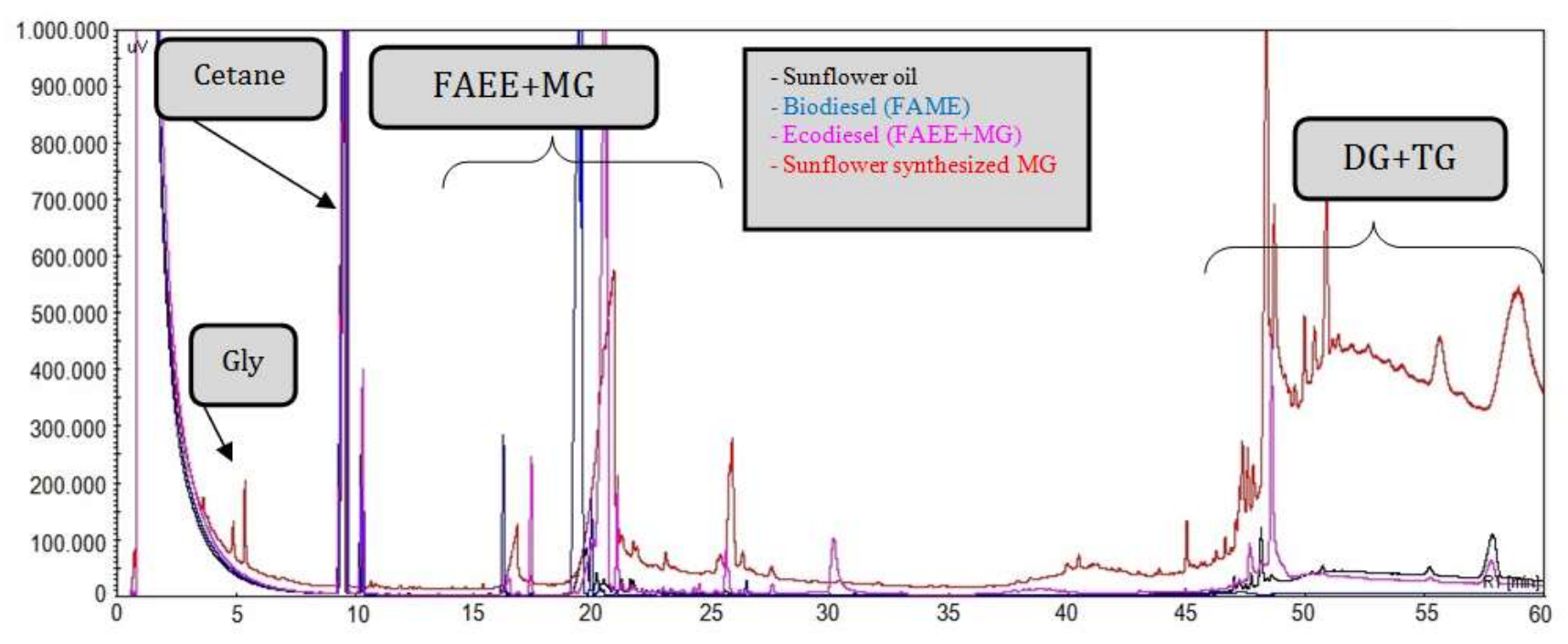

RT

Here we can see that the different esters of fatty acids (FAEs), that compose the lipid profile of the sunflower oil, displays retention times (RT) slightly higher than the cetane (n-hexadecane), used as internal standard. Thus, whereas RT of cetane is around 10 minutes, all RT of FAEs appear in the range of 16 to 26 minutes. These are composed of methyl, ethyl and glycerol esters (the later constitute MGs) of palmitic, stearic, linoleic and oleic acids. Thus, palmitic acid (C16:0) derivatives are grouped in a narrow range of RT, 16 to 17 minutes. Derivatives of oleic (C18:1) and linoleic acid (C18:2) are grouped in RT of 19 to 21 minutes, with the exception of glycerol ester of oleic acid, or what is the same, the MG of the oleic acid has a different behaviour, with a RT $=26$ minutes. Glycerol RT is obtained at 5 minutes, before Cetane. The absence of this compound in the obtained chromatograms clearly demonstrates the selective nature of studied enzymatic transesterification reaction.

In Fig. 2 it can also be seen the presence of DG with higher retention times, 40-60 minutes that do not allow its integration into the GC chromatogram, so that it is necessary to determine DG together and TG, by using an internal standard such as the cetane here employed. It should be noted that the differences in RT values between MG and DG are much higher than those existing between MG and FAME or FAEE, such as it is expected by the differences between their corresponding molecular weights. At the same time, it is clear that the FAMEs, FAEEs and MGs display somewhat higher RT values than cetane, but within the molecular weight range, which allows considering similar chemicalphysical properties between the FAE and the hydrocarbons that constitute diesel. 
Since retention times of different derivatives of fatty acids are considered very closely related to the chemical-physical properties of these compounds, the great similarity of RT values obtained, is a clear demonstration of the similarity among the rheological properties of the different MGs with their corresponding FAMEs or FAEEs, which are crucial to allow its use as fuel able to substitute for petroleum products. Consequently, Conversion is a reaction parameter where are included (as \%) all molecules (FAEE, MG and DG) obtained in the ethanolysis of TG, it will be considered as a very different parameter, respect to the Selectivity, where are only included (as \%) FAEEs and MGs, all they with RT values lower than 26 min. These molecules exhibits RT values similar to hydrocarbons present in conventional diesel, so that they all could exhibit similar physicochemical and rheological properties. However a high Conversion, even $100 \%$, could contain a high proportion of DG molecules, with high molecular weight and high viscosity values. Consequently, a very high Selectivity, indicating a very high percentage of FAEEs and MGs, could promote a viscosity value close to the petroleum diesel, so that the highest Conversion value is not enough a guaranty of lower viscosity values. Thus, both parameters will be provided as GC analysis results of reaction products.

Taking into account that retention times of complex mixture of hydrocarbons constituting fossil diesel fuel are ranging from 1 to 25 minutes, it is used as a reference value for different biofuels (FAME, FAEE, MG) as selectivity value, all those FAEs that present RT values coincident with the hydrocarbons constituting diesel, or those with RT lower than 25 minutes, as it is expected they also present similar physicochemical and rheological properties to the conventional diesel.

\subsection{Variables effect on enzyme activity}

To carry out an evaluation of enzyme activity and optimize reaction conditions for this enzyme, it has been made a multivariable experimental design in which has been analyzed the influence of the temperature, $\mathrm{pH}$ environment and the oil / ethanol volume ratio as well as the magnitude of these influences. According to previous results [12], before carrying out the multivariable experimental design for ANOVA analysis, a more detailed study about the influence of enzyme and water amounts was developed to operate under optimum conditions, respect to these two strongly influential variables. Thus, both variables have been studied separately, obtaining in this way further information of their influence and simplifying the subsequent multivariable experimental design (ANOVA). The current study has also followed in this case the OVAT methodology (Variable At One Time), for which it has been set initial conditions of $\mathrm{pH}$ environment, temperature and oil/alcohol volume ratio, and it has been modifying variables one by one.

\subsubsection{Effect of water content}

The water content is a highly important parameter in enzymatic transesterification, through the water activity $\left(a_{\mathrm{w}}\right)$, accounting for the intensity with which water associates with lipases to obtain the best enzymatic activity, especially in solvent-free systems. A series of experiments under optimal conditions for temperature, $\mathrm{pH}$ and oil/ethanol ratio, obtained from previous RSM studies [12], were carried out to evaluate the effect of this parameter. Fig. 3 shows the effect of water content in reaction yield achieved in the transesterification reaction of sunflower oil. A minimum in kinematic viscosity, which corresponds to a maximum in conversion, was achieved at a concentration of $0.15 \%$ of added 
water in the reaction medium. Consequently, the water content is a very important parameter that is necessary to control in ethanolysis processes, so that this parameter has been set in the optimum value ( $0.15 \mathrm{wt} \%$ water) to carry out the multivariable experimental design to analyze the influence of the temperature, $\mathrm{pH}$ environment and the oil / ethanol volume ratio as well as the magnitude of these influences.

Figure 3. Influence of water content on ethanolysis reaction yield (conversion and kinematic viscosities).

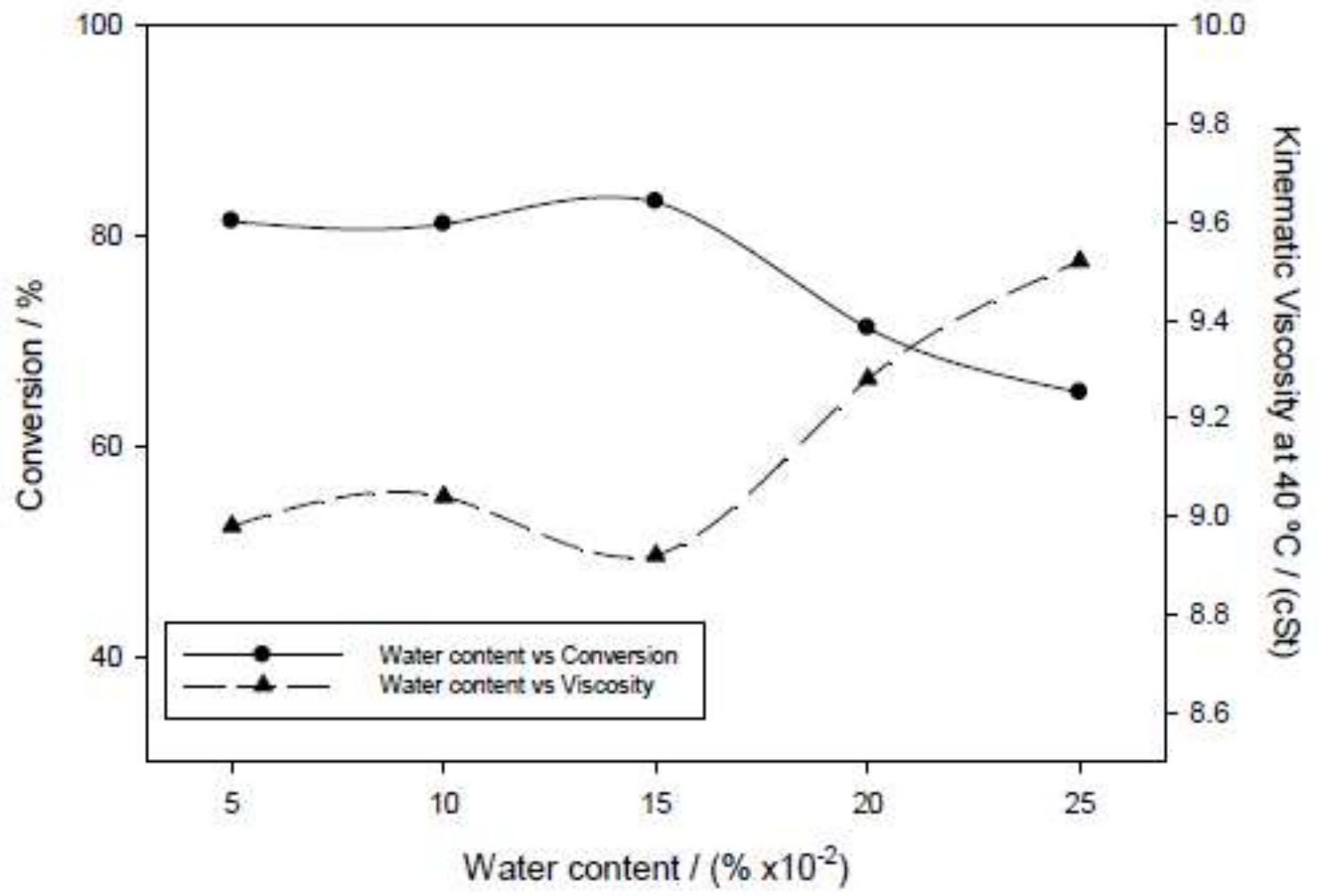

\subsubsection{Effect of the quantity of lipase}

Fig. 4 depicts the effect of the quantity of enzyme utilized on conversion and kinematic viscosity. $20 \mathrm{mg}$ lipase was selected as optimum value in all reactions, as this quantity was shown to be sufficient to provide a combined good yield. It can be also checked the subsequent yield decrease as it is increased the amount of lipase added. Probably due to the effects of enzymatic agglomeration already described for other lipases in free form [12]. Therefore, for next experiments, it is fixed for $20 \mathrm{mg}$ as the optimum amount of catalyst to be used.

Figure 4. Influence of the quantity of lipase on ethanolysis reaction yield (conversion and kinematic viscosities) 


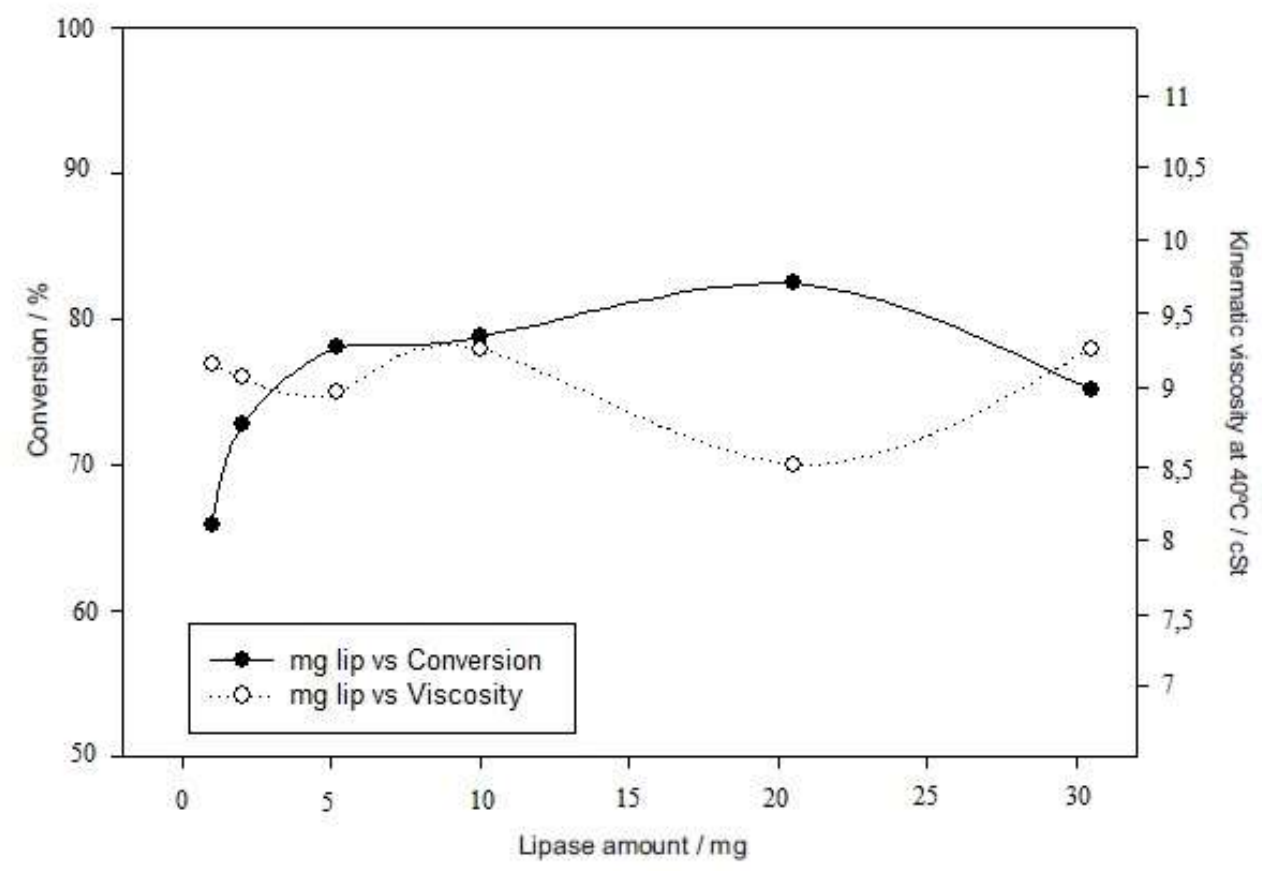

2.2.3. Analysis of variance (ANOVA ) and optimization of the reaction parameters by RSM

The analysis of variance methods has become very attractive in reaction parameters optimization and in the evaluation of the effects of the parameters in the TG transesterification reaction $[9,12,26]$ due to its effectiveness in the analysis of variables. Thus, results are obtained operating under the 36 runs, each one with different experimental conditions, selected by the multifactorial design of experiments with three factors, developed by the software Stat Graphics version XV.I., where two of them are developed at three levels, and the other at two levels, as it is indicated in Table 1.

Table 1. Process parameters in factorial design: coded and actual values.

\begin{tabular}{ccccc}
\hline \multirow{2}{*}{ Variables } & Unit & \multicolumn{4}{c}{ Levels } \\
\cline { 3 - 5 } Temperature & ${ }^{\circ} \mathrm{C}$ & 20 & 30 & 40 \\
$\begin{array}{c}\text { Oil/Ethanol ratio } \\
(\mathbf{v} / \mathbf{v})\end{array}$ & $\mathrm{mL} / \mathrm{mL}$ & $12 / 1,75$ & - & $12 / 3.5$ \\
& & & & \\
$\mathbf{p H}$ & $(\mu \mathrm{L}$ & & & $12(50)$ \\
& $\mathrm{NaOH}$ & $8(12.5)$ & $10(5)$ & $12(5)$ \\
\hline
\end{tabular}

Results achieved following this methodology are shown in Table 2. The quantity of biocatalyst (BIOLIPASE-R®) in all these experiments was fixed to $20 \mathrm{mg}$. All experiments were duplicated and in a random way in order to avoid experimental errors. 
Table 2. Experiments matrix of factorial design and the response obtained for conversion, selectivity and viscosity.

\begin{tabular}{|c|c|c|c|c|c|c|}
\hline \multirow[b]{2}{*}{ Run } & \multicolumn{3}{|c|}{ Studied variables } & \multicolumn{3}{|c|}{ Output variables } \\
\hline & Temperature & $\mathrm{pH}$ & Oil/Ethanol ratio & Conversion $(\%)$ & $\operatorname{FAEE}(\%)$ & $\begin{array}{l}\text { Cinematic } \\
\text { viscosity } \\
\left(\mathrm{mm}^{2} \mathrm{~s}^{-1}\right)\end{array}$ \\
\hline 1 & -1 & 0 & 1 & 81.2 & 43.5 & 9.8 \\
\hline 2 & 1 & -1 & -1 & 44.7 & 31.9 & 9.7 \\
\hline 3 & 0 & 0 & 1 & 70 & 43.5 & 12.2 \\
\hline 4 & 1 & 1 & 1 & 75.8 & 42.1 & 11.8 \\
\hline 5 & -1 & 1 & 1 & 83.6 & 47.6 & 8.1 \\
\hline 6 & 0 & 1 & -1 & 67.1 & 39.6 & 11.4 \\
\hline 7 & -1 & -1 & 1 & 74.8 & 40.6 & 12.0 \\
\hline 8 & 1 & 1 & -1 & 55.5 & 34.8 & 12.5 \\
\hline 9 & 1 & 0 & -1 & 47.2 & 32.4 & 12.3 \\
\hline 10 & -1 & 1 & -1 & 60 & 36.2 & 8.8 \\
\hline 11 & 1 & 0 & 1 & 75.9 & 43.8 & 11.2 \\
\hline 12 & 0 & -1 & -1 & 46.8 & 32.6 & 11.3 \\
\hline 13 & 0 & 0 & -1 & 51.6 & 32.4 & 12.7 \\
\hline 14 & 0 & -1 & 1 & 60.8 & 38.5 & 11.2 \\
\hline 15 & 0 & 1 & 1 & 81.1 & 49.7 & 10.6 \\
\hline 16 & -1 & -1 & -1 & 47.9 & 32.6 & 11.6 \\
\hline 17 & 1 & -1 & 1 & 73.4 & 43.7 & 9.1 \\
\hline 18 & -1 & 0 & -1 & 55.0 & 34.9 & 11.2 \\
\hline \multicolumn{4}{|c|}{ Repetition of experiments } & \multirow[b]{2}{*}{ Conversion $(\%)$} & \multirow[b]{2}{*}{$\begin{array}{c}\text { Selectivity } \\
(\%)\end{array}$} & \multirow{2}{*}{$\begin{array}{l}\text { Cinematic } \\
\text { viscosity } \\
\left(\mathrm{mm}^{2} \mathrm{~s}^{-1}\right) \\
\end{array}$} \\
\hline Run & Temperature & $\mathrm{pH}$ & Oil/Ethanol ratio & & & \\
\hline 19 & 1 & 0 & -1 & 46.2 & 31.5 & 12.7 \\
\hline 20 & 0 & 0 & 1 & 73.2 & 40.7 & 11.8 \\
\hline 21 & 0 & -1 & -1 & 47.2 & 31.9 & 10.7 \\
\hline 22 & -1 & 0 & -1 & 56.2 & 35.3 & 10.9 \\
\hline 23 & 1 & 1 & -1 & 54.3 & 34.5 & 12.5 \\
\hline 24 & -1 & 1 & -1 & 58.1 & 35.7 & 9.4 \\
\hline 25 & 1 & -1 & 1 & 74.7 & 43.1 & 9.3 \\
\hline 26 & -1 & -1 & -1 & 48.2 & 32.6 & 10.9 \\
\hline 27 & 1 & 0 & 1 & 75 & 43.8 & 11.1 \\
\hline 28 & 0 & 1 & 1 & 83.3 & 46.9 & 9.9 \\
\hline 29 & -1 & -1 & 1 & 76.3 & 42.2 & 11.7 \\
\hline 30 & -1 & 1 & 1 & 83.2 & 47.3 & 9.2 \\
\hline
\end{tabular}




\begin{tabular}{lcccccc}
\hline 31 & 0 & 0 & -1 & 50.3 & 32.8 & 11.4 \\
32 & 1 & 1 & 1 & 74.3 & 42.9 & 10.9 \\
33 & 1 & -1 & -1 & 45.9 & 32.2 & 9.4 \\
34 & 0 & 1 & -1 & 65.8 & 39.9 & 11.6 \\
35 & 0 & -1 & 1 & 59.7 & 36.9 & 10.0 \\
36 & -1 & 0 & 1 & 80.8 & 44.6 & 11.4 \\
\hline
\end{tabular}

From these data and using the Statgraphics software, it has been performed a Multivariate statistical analysis (ANOVA) to determine the correlation or "effects" of the experimental studied variables with output variables (conversion, selectivity and kinematic viscosity). The software gives us different data outputs that allow us to analyze the influence of the independent variables in the variable dependent study. The quadratic polynomial model was highly significant and sufficient to explain the relationship between conversion/selectivity/kinematic viscosity and important experimental variables, as it is summarized in Tables 3. Thus, the results of factorial design suggested that the major factors affecting the transesterification, for the production of biofuels integrating glycerol as monoacylglycerols, were $\mathrm{pH}$ and oil/ethanol ratio $(\mathrm{v} / \mathrm{v})$ in conversion and selectivity, however in cinematic viscosity, were temperature and oil/ethanol volumetric ratio the most influents reaction parameters.

Table 3. Analysis of variance (ANOVA) for Conversion (A), Selectivity (B) and Kinematic viscosity (c).

(A) Analysis of variance (ANOVA) for Conversion

\begin{tabular}{lccccc}
\hline \multicolumn{1}{c}{ Source } & $\begin{array}{c}\text { Sum of } \\
\text { squares }\end{array}$ & df & Mean square & F-value & P-value \\
\hline A:Temperature & 162,24 & 1 & 162,24 & 8,06 & 0,0087 \\
B:pH & 836,62 & 1 & 836,62 & 41,55 & 0,0000 \\
C:Oil/ethanol ratio & 4648,97 & 1 & 4648,97 & 230,89 & 0,0000 \\
AA & 16,4356 & 1 & 16,4356 & 0,82 & 0,3746 \\
AB & 17,0156 & 1 & 17,0156 & 0,85 & 0,3664 \\
AC & 0,0266667 & 1 & 0,0266667 & 0,00 & 0,9712 \\
BB & 4,15681 & 1 & 4,15681 & 0,21 & 0,6533 \\
BC & 14,2604 & 1 & 14,2604 & 0,71 & 0,4077 \\
Bloqs & 0,0025 & 1 & 0,0025 & 0,00 & 0,9912 \\
Total error & 523,511 & 26 & 20,1351 & & \\
Total (corr.) & 6223,24 & 35 & & & \\
\hline \multicolumn{2}{c}{$\mathrm{R}^{2}=91.59 \% ; \mathrm{R}^{2}$ (adj.) $=89,10 \%$} & & & & \\
& & & & &
\end{tabular}

(B) Analysis of variance (ANOVA) for Selectivity 


\begin{tabular}{lccccc}
\hline \multicolumn{1}{c}{ Source } & $\begin{array}{c}\text { Sum of } \\
\text { squares }\end{array}$ & df & Mean square & F-value & P-value \\
\hline A:Temperature & 11,2067 & 1 & 11,2067 & 2,78 & 0,1072 \\
B:pH & 142,107 & 1 & 142,107 & 35,31 & 0,0000 \\
C:Oil/ethanol ratio & 780,271 & 1 & 780,271 & 193,89 & 0,0000 \\
AA & 0,0138889 & 1 & 0,0138889 & 0,00 & 0,9536 \\
AB & 14,8225 & 1 & 14,8225 & 3,68 & 0,0660 \\
AC & 0,54 & 1 & 0,54 & 0,13 & 0,7171 \\
BB & 4,30222 & 1 & 4,30222 & 1,07 & 0,3107 \\
BC & 0,881667 & 1 & 0,881667 & 0,22 & 0,6436 \\
Bloqs & 0,871111 & 1 & 0,871111 & 0,22 & 0,6456 \\
Total error & 104,633 & 26 & 4,02435 & & \\
Total (corr.) & 1059,65 & 35 & & & \\
\hline
\end{tabular}

$\mathrm{R}^{2}=90.13 \% ; \mathrm{R}^{2}(\operatorname{adj})=.87.20 \%$

(C) Analysis of variance (ANOVA) for Cinematic viscosity

\begin{tabular}{lccccc}
\hline \multicolumn{1}{c}{ Source } & $\begin{array}{c}\text { Sum of } \\
\text { squares }\end{array}$ & df & Mean square & F-value & P-value \\
\hline A:Temperature & 2,34375 & 1 & 2,34375 & 9,69 & 0,0045 \\
B:pH & 0,00166667 & 1 & 0,00166667 & 0,01 & 0,9345 \\
C:Oil/ethanol ratio & 2,61361 & 1 & 2,61361 & 10,81 & 0,0029 \\
AA & 2,03347 & 1 & 2,03347 & 8,41 & 0,0075 \\
AB & 27,3006 & 1 & 27,3006 & 112,88 & 0,0000 \\
AC & 1,08375 & 1 & 1,08375 & 4,48 & 0,0440 \\
BB & 7,86722 & 1 & 7,86722 & 32,53 & 0,0000 \\
BC & 1,215 & 1 & 1,215 & 5,02 & 0,0338 \\
Bloqs & 0,2025 & 1 & 0,2025 & 0,84 & 0,3686 \\
Total error & 6,28813 & 26 & 0,241851 & & \\
Total (corr.) & 50,9497 & 35 & & & \\
\hline
\end{tabular}

$$
\mathrm{R}^{2}=87.66 \% ; \mathrm{R}^{2}(\text { adj. })=84.00 \%
$$

The values of correlation coefficients, $\mathrm{R}^{2}$ were 0.916 for Conversion, 0.901 for Selectivity and 0 . 877 for kinematic Viscosity, respectively, which imply a good fit between models and experimental data in Pareto graphics, respect to Conversion, Selectivity and Viscosity, as it is indicated in Fig. 5 (a). The adjusted correlation coefficients $\mathrm{R}^{2}$ were $0.891,0.872$ and 0.84 for Conversion, Selectivity and kinematic viscosity, respectively. Obtained results pointed out that the temperature, $\mathrm{pH}$ and oil/ethanol ratios were also important parameters influencing the conversion, selectivity and viscosity in the systems $(\mathrm{p}<0.05)$. 
The software also allows obtaining equations, after the elimination of non influent parameters in the model for conversion, selectivity and kinematic viscosity, the $\mathrm{R}^{2}$ values for these dependent variables were $0.871,0.873$ and 0.876 respectively, and the equations obtained (eq. 1, eq. 2 and eq. 3) were remarkably simpler as compared to initial ones. These equations describe the model created and gives solutions for the dependent variable based on the independent variable combinations, whether they are or not significant in the response. Thus, taking into account that $\mathrm{R}$ is the Oil/Ethanol ratio (v/v), $\mathrm{pH}$ is the obtained by the addition of different $\mu \mathrm{L}$ of $\mathrm{NaOH} 10 \mathrm{~N}$ and $\mathrm{T}$ the reaction temperature:

$$
[\text { Conversion }(\%)=64,0306-2,60 \times T+5,90 \times p H+11,36 \times R]
$$

$$
[\operatorname{Selectivity}(\%)=38,76+2,43 \times p H+4,66 \times R]
$$

$$
\begin{gathered}
{\left[\text { Viscosity }(c S t)=11,8944+0,3125 * T-0,2694 \times R+0,5042 \times T^{2}+1,306 \times\right.} \\
\left.T \times p H-0,2125 \times T \times R-0,9917 \times p H^{2}-0,225 \times p H \times R\right]
\end{gathered}
$$

The surface plots in Fig. 5 (b), described by the regression model were drawn to display the effects of the independent variables on Conversion, Selectivity and kinematic viscosity. Here it can be clearly seen the influence of the different variables in the reaction performance of the systems. This model showed that the optimum values for the parameters to maximize transesterification yield (Conversion, Selectivity, kinematic Viscosity) were lower temperatures $\left(20{ }^{\circ} \mathrm{C}\right)$, maximum amount of aqueous $\mathrm{NaOH} 10 \mathrm{~N}$ added $(50 \mu \mathrm{L})$ and the maximum oil/ethanol $(\mathrm{ml} / \mathrm{ml})$ ratio $=12 / 3.5(1 / 6$ molar ratio) studied. Conversions up to $80 \%$, Selectivities until $70 \%$ and values of kinematic viscosity about 10 $\mathrm{mm}^{2} \mathrm{~s}^{-1}$ could be achieved under these conditions, which in theory will render feasible the utilization of the obtained biofuel in blends with diesel. For example, by the addition of only $35 \%$ of diesel fossil, to this biofuel, it is obtained a viscosity reduction at $4.8 \mathrm{~mm}^{2} \mathrm{~s}^{-1}$, a value within the acceptance limits of the EN 14214. 
Figure 5. Pareto graphics (a): Conversion (a.1), Selectivity (a.2) and Viscosity (a.3). as well as response surface plot of more influential parameters vs $\mathrm{pH}$, Temperature and oil/ethanol ratio (b): Conversion (b.1), Selectivity (b.2) and Viscosity (b.3).

(a)

(a.1)

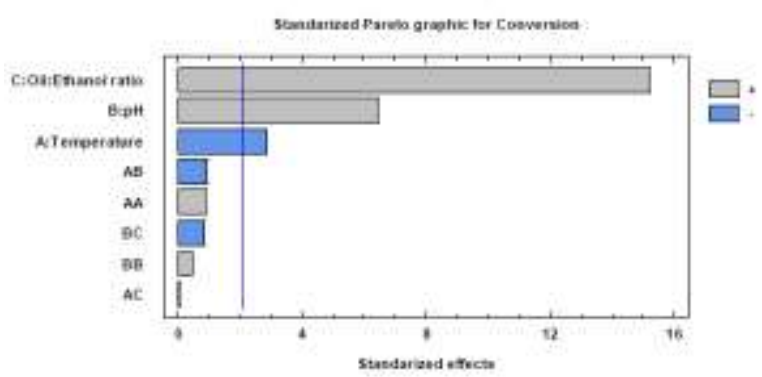

(a.2)

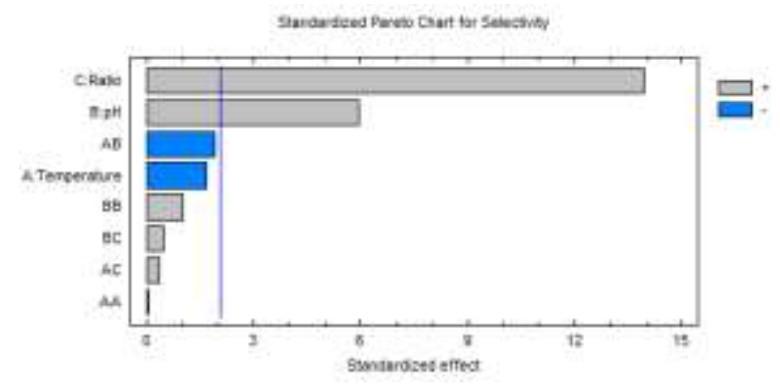

(a.3)

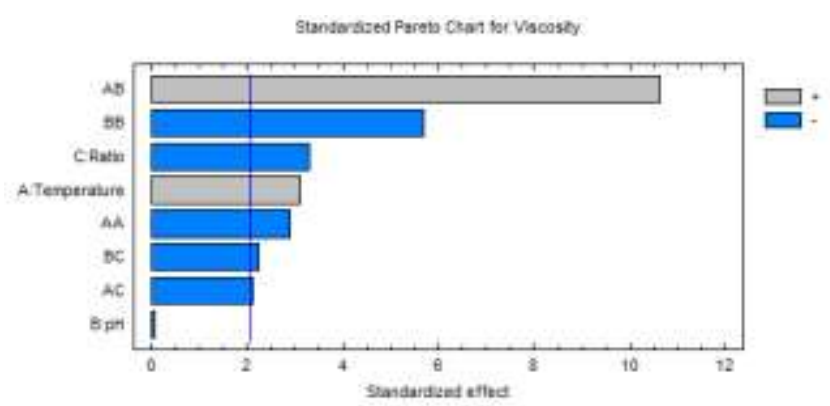

(b)

(b.1)

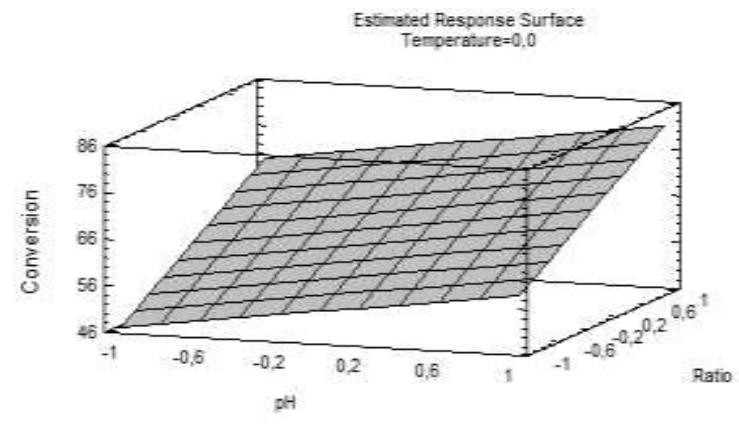

(b.2)

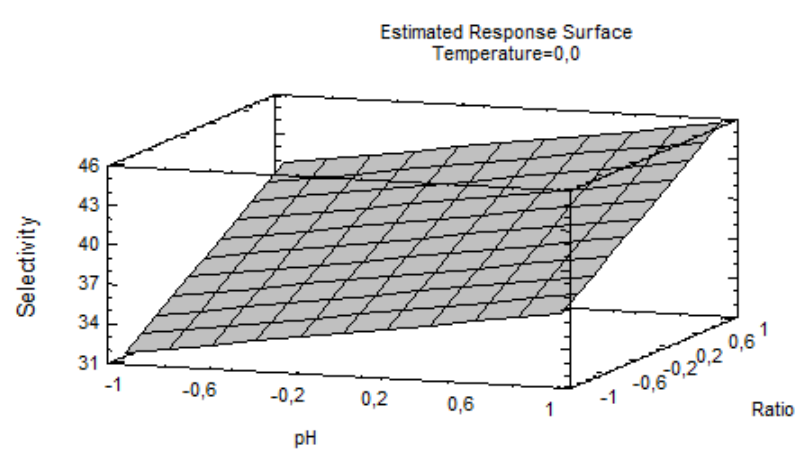

(b.3)

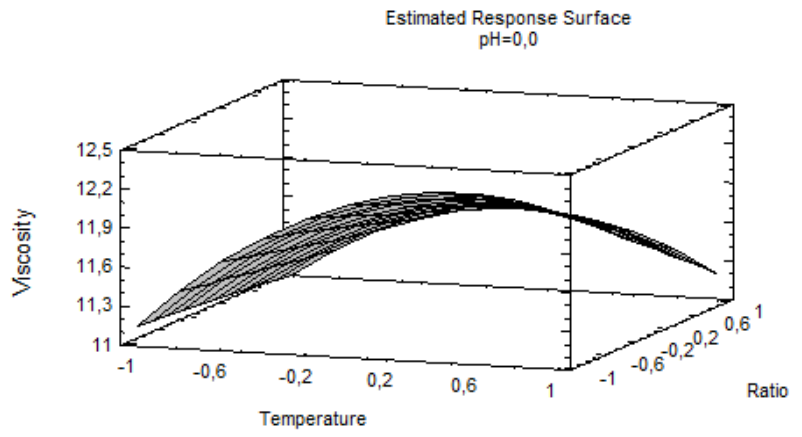




\subsubsection{Experimental validation of proposed model}

To validate the proposed models, it has been carried out a series of three experiments, whose reaction conditions have been selected among the range of variables. In this way, in Table 4 are shown reaction conditions and their yields (conversion, selectivity) for each reaction performed. Thus, achieved experimental values are similar to theoretical calculated data provided by the proposed models.

Table 4. Validation experiments of proposed models for the enzyme BIOLIPASE- ${ }^{\circledR}$.

\begin{tabular}{|c|c|c|c|c|c|c|}
\hline \multirow{2}{*}{$\begin{array}{c}\text { Temperature } \\
{ }^{\circ} \mathrm{C}\end{array}$} & \multirow[t]{2}{*}{ pH } & \multirow{2}{*}{$\begin{array}{l}\text { Oil/ethanol } \\
\text { ratio }\end{array}$} & \multicolumn{2}{|c|}{$\begin{array}{c}\text { Conversion } \\
(\%)\end{array}$} & \multicolumn{2}{|c|}{$\begin{array}{c}\text { Selectivity } \\
(\%)\end{array}$} \\
\hline & & & Exp. & Adj. & Exp. & Adj. \\
\hline 25 & 11.5 & $12 / 2.9$ & 68.8 & 72.7 & 39.5 & 41.5 \\
\hline 30 & 10.5 & $12 / 2.75$ & 63.7 & 66.8 & 42.3 & 39.4 \\
\hline 50 & 9 & $12 / 3.3$ & 70.9 & 68.1 & 44.7 & 40.9 \\
\hline
\end{tabular}

\subsubsection{Influence of temperature}

To get a more accurate information on the influence of temperature on biocatalytic behavior of BIOLIPASE-R, a series of reactions are developed at different temperatures, operating under the optimum experimental conditions here determined. In this way, it is confirmed that the biocatalyst really shows an optimum of efficiency in the conditions estimated by the Multivariate statistical analysis (ANOVA). Data from these experiments are shown in Figure 6.

Figure 6. Influence of the temperature on ethanolysis reaction yield (conversion, selectivity and kinematic viscosities).
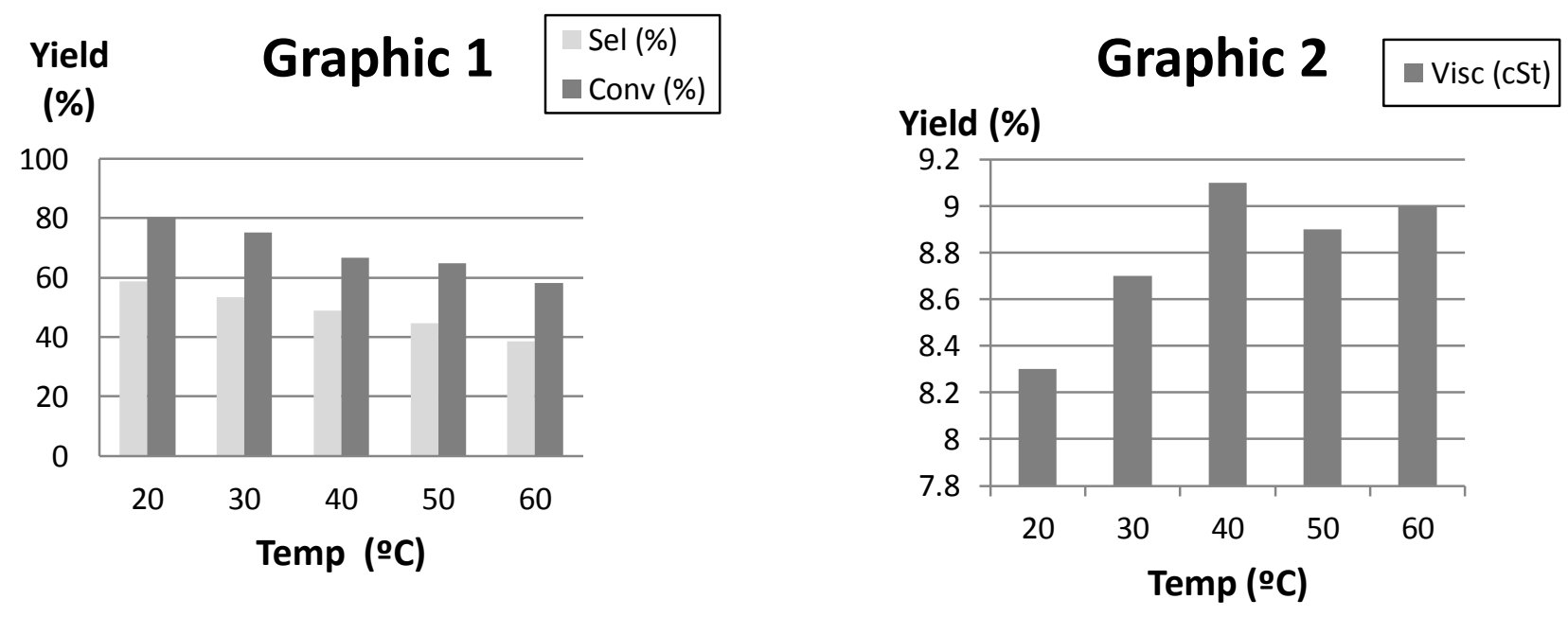


\section{Experimental Section}

\subsection{Materials}

Commercial sunflower oil was locally obtained. The chromatographically pure ethyl esters of palmitic acid, stearic acid, oleic acid, linoleic acid and linolenic acid were commercially obtained from Accustandard, and the hexadecane (cetane) from Sigma-Aldrich. Other chemicals like absolute ethanol and sodium hydroxide were pure analytical compounds (99.5\%) obtained commercially from Panreac. BIOLIPASE- $\mathrm{R}^{\circledR}$, a low cost powdered enzyme preparation containing obtained lipases from a strain of Rhizopus oryzae, was kindly provided by Biocon ${ }^{\circledR}$-Spain.

\subsection{Ethanolysis reactions}

These reactions were performed according to the experimental procedure previously described [1115] to determine the optimal conditions for obtaining the selective ethanolysis reaction, such as amount of lipase, water content, $\mathrm{pH}$ environment (by addition of different $\mu$ l of $10 \mathrm{~N} \mathrm{NaOH}$ dissolution), the oil/ethanol molar ratio (v/v) and temperature. Thus, enzymatic assays are carried out with $9.4 \mathrm{~g}(12 \mathrm{~mL}, 0.01 \mathrm{~mol})$ of commercial sunflower oil at controlled temperatures $\left(20-40{ }^{\circ} \mathrm{C}\right)$ in a 25 $\mathrm{mL}$ round bottom flask. Reaction mixtures were stirred with a conventional magnetic stirrer at a higher stirring speed than $300 \mathrm{rpm}$, to avoid mass transfer limitations, along a reaction time of $2 \mathrm{~h}$. Variable oil/alcohol volume ratios at different $\mathrm{pH}$, several water contents and different quantities of lipase are studied. The different oil/ethanol ratios (v/v) are obtained by introducing absolute ethanol volumes in the range 1.75-3.5 ml, the influence of different amounts of lipase are studied in the range 0.05-0.5 $\mathrm{g}$, the water content is varied from 0.05 to 0.25 weight $\%$ by adding deionized water, the sample is left under stirring with the oil for about 15 minutes to homogenize and stabilize the system. The influence of $\mathrm{pH}$ values were achieved by adding different volumes (12.5-50 $\mu \mathrm{l})$ of $10 \mathrm{~N} \mathrm{NaOH}$ aqueous solutions. In this regard, a blank reaction in the presence of the highest quantity of solution of $\mathrm{NaOH}$ was performed to rule out a potential contribution from the homogeneous $\mathrm{NaOH}$ catalysed reaction. Less than $10 \%$ conversion of the starting material was obtained, so that a homogenous base catalysis contribution can be considered as negligible under the investigated conditions. All variable were studied and optimized according to a factorial experimental design and a response surface methodology.

\subsection{Analytical method}

Reaction products were monitored by capillary column gas chromatography, using a Varian 430GC gas chromatograph, connected to a HT5 capillary column (25 m x $0.32 \mathrm{~mm}$ ID x $0.1 \mu \mathrm{m}$, SGE, Supelco) with a flame ionization detector (FID) at $450{ }^{\circ} \mathrm{C}$ and splitless injection at $350{ }^{\circ} \mathrm{C}$. Helium is used as carrier gas, with a flow of $1.5 \mathrm{ml} / \mathrm{min}$. It has been applied a heating ramp from $90{ }^{\circ} \mathrm{C}$ to $200{ }^{\circ} \mathrm{C}$ at a rate of $7{ }^{\circ} \mathrm{C} / \mathrm{min}$, followed by another ramp from $200{ }^{\circ} \mathrm{C}$ to $360{ }^{\circ} \mathrm{C}$ at a rate of $15{ }^{\circ} \mathrm{C} / \mathrm{min}$, maintaining the temperature of the oven at $360{ }^{\circ} \mathrm{C}$ for 10 minutes using as internal standard $\mathrm{n}$ hexadecane (cetane) to quantify the content of ethyl esters and the different glycerides (-mono, di and triglycerides) with the help of several commercial standard fatty acid esters. This method allows us to 
make a complete analysis of the sample in a single injection and in a time not higher than 60 minutes, which simplifies the process and increases the speed of analysis [11-15].

Considering that sunflower oil is constituted by a mixture of fatty acids in variable proportion (mainly linoleic, oleic, palmitic and stearic acids), the reactions results are expressed as the relative amounts of the corresponding ethyl esters (FAEE, Fatty Acid Ethyl Esters), monoglycerides (MG) and diglycerides (DG) that are integrated in the chromatogram. Considering that sunflower oil is constituted by a mixture of fatty acids in variable proportion (mainly linoleic, oleic, palmitic and stearic acids), the results obtained are expressed as the relative amounts of the corresponding ethyl esters (FAEE, Fatty Acid Ethyl Esters), monoglycerides (MG) and diglycerides (DG) that are integrated in the chromatogram. The amount of triglycerides (TG) which has not reacted is calculated from the difference to the internal standard (cetane). Thus, the Conversion includes the total amount of triglyceride transformed (FAEE $+\mathrm{MG}+\mathrm{DG}$ ) in the ethanolysis process and Selectivity makes reference to the relative amount of FAEE + MG obtained. The latter are those ones having retention times close to the cetane standard, which is the reference hydrocarbon for diesel fuel.

\subsection{Viscosity measurements}

Transesterification reactions of oils and fats are basically carried out to obtain an important reduction in the viscosity of these materials, as they share similar values in all of other chemicalphysical significant parameters with the fossil diesel except the viscosity. In this respect, most of oils exhibit viscosities in the range $30-45 \mathrm{~mm}^{2} / \mathrm{s} \mathrm{cSt}$ values, while the fossil diesel is in the range $2.5-6 \mathrm{cSt}$ values. Thus, due to the importance of viscosity for the correct running of diesel engines, this parameter becomes in the critical factor to change in the chemical-physical properties of vegetable oils before their use as biofuel. The transesterification process of oils and fats is actually developed in order obtaining a noticeable lowering in oils to get employ the resulting product, with reduced viscosity, as biofuel in current existing diesel engines. Thus, accurate viscosity measurements are critical to assess the quality of biofuels produced, since unsuitable viscosity values can decisively affect the correct working conditions of the diesel engine. Therefore, the characterization of this parameter is essential to evaluate the result obtained in the process of ethanolysis.

Viscosities were determined in a capillary viscometer Oswald Proton Cannon-Fenske Routine Viscometer 33200, size 150. This is based on determining the time needed for a given volume of fluid passing between two points marked on the instrument. The kinematic viscosity is given by the ratio between the dynamic viscosity ( $h$, in Poise, g/cm s) and the density $\left(\mathrm{r}\right.$, in $\left.\mathrm{g} / \mathrm{cm}^{3}\right) ; \mathrm{v}=\mathrm{h} / \mathrm{r}$, in $\mathrm{cm}^{2} / \mathrm{s}$ or centistokes, cSt, $\mathrm{mm}^{2} / \mathrm{s}$. Samples, previously centrifuged at $3500 \mathrm{rpm}$ for 10 minutes and filtered at 50 ${ }^{\circ} \mathrm{C}$, ere immersed in a thermostatic bath at $40{ }^{\circ} \mathrm{C}$ for 15 minutes, making sure that the temperature is stable. Then, samples are introduced into the viscometer and this, in turn, in the water bath, making sure that it is rigorously positioned vertically, with the bottom end at a minimum distance of $2 \mathrm{~cm}$ from the floor of the bath [11-15].

\subsection{Experimental design}

The effect of process parameters in the enzymatic transesterification reaction to obtain the optimum conditions for the viscosity, selectivity and conversion were studied using a multifactorial design of 
experiments with three factors run by the software Stat Graphics version XV.I. Two of them at developed at three levels, and the last one at two levels, so that it gives 36 runs. The experiments were performed in random order. The experimental parameters selected for this study were reaction temperature, oil/ethanol ratio ( $\mathrm{v} / \mathrm{v})$ and different $\mathrm{pH}$ obtained by the addition of variable volumes, in $\mu \mathrm{l}$, of $\mathrm{NaOH} 10 \mathrm{~N}$. Table 1 shows the coded and actual values of the process parameters used in the design matrix.

\subsection{Statistical analysis}

The experimental data obtained from experimental design were analyzed by Response surface methodology (RSM) $[9,12,26]$. A mathematical model, following a second-order polynomial equation, was developed to describe the relationships between the predicted response variable (Viscosity, Conversion and Selectivity) and the independent variables of reaction conditions, as it is shown in the Eq. (4), where $Y$, is the predicted response variable; $\beta \mathrm{o}, \beta \mathrm{i}, \beta \mathrm{ii}, \beta \mathrm{ij}$ the intercept, linear, quadratic and interaction constant coefficients of the model, respectively; $\mathrm{Xi}, \mathrm{Xj}(\mathrm{i}=1,3 ; \mathrm{j}=1,3 ; \mathrm{i} \neq \mathrm{j}$ ) represent the coded independent variables.

$$
Y=\beta_{0}+\sum_{i=1}^{3} \beta_{0} x_{i}+\sum_{i=1}^{3} \beta_{i i} x_{i}^{2}+\sum_{i<j=1}^{3} \beta_{i j} x_{i} x_{j}
$$

Response surface plots were developed using the fitted quadratic polynomial equation obtained from regression analysis, holding one of the independent variables at constant values corresponding to the stationary point and changing the order two variables. The quality of the fit of the polynomial model equation was evaluated by the coefficient of determination $\mathrm{R}^{2}$, and its regression coefficient significance was checked with $F$-test. Confirmatory experiments were carried out in order to validate the model, using combinations of independent variables which were not part of the original experimental design, but within the experimental region.

\section{Conclusions}

In order to improve a new methodology that integrates the glycerol as different monoacylglycerol molecules, the commercial BIOLIPASE- ${ }^{\circledR}$, a low cost and industrially available powdered enzyme preparation containing obtained lipases from a strain of Rhizopus oryzae, a multipurpose additive from Biocon ${ }^{\circledR}$-Spain, usually used in food industry, it was evaluated as biocatalyst in the 1,3 selective ethanolysis of sunflower oil. Results show that substrate molar ratio of ethanol to sunflower oil, $\mathrm{pH}$ and reaction temperature, as well as the water content and biocatalyst amount, have a significant effect on the percentage of reaction yield (conversion, selectivity and cinematic viscosity). On the basis of RSM analysis, we found that operates optimally with a water content of the reaction medium of 0.15 $\%, 0.05-0.1 \%$ lipase by weight relative to the weight of oil used, $20{ }^{\circ} \mathrm{C}$, volume ratio $(\mathrm{ml} / \mathrm{ml})$ oil/ethanol 12/3.5 and pH 12 (obtained by addition of $50 \mu 1$ of $10 \mathrm{~N} \mathrm{NaOH}$ dissolution). 
Thus, the present results obtained indicate that the commercial low cost lipase studied, is specially efficient in the obtaining of 1,3 selective ethanolysis processes, where glycerol is kept as MG in the biofuel mixture, with the different obtained FAEEs. The obtained mixture of MGs, and FAEEs with the excess of unreacted ethanol, constitute the Ecodiesel biofuel that can be used directly, without any kind of subsequent cleaning, separation or purification process. In this way, this biofuel can be economically viable and environmentally sustainable with the help of BIOLIPASE- $\mathrm{R}^{\circledR}$ since by using a low cost and industrially available lipase, an important cost reduction of the process is produced, with high yield at very short reaction times (less than $1 \mathrm{~h}$ ) and under soft reaction conditions. Besides, not only it is achieved a higher atomic yield, respect to the conventional biodiesel reaction, (because no glycerol byproduct is generated), but also it is not necessary a purification step of residual glycerol, so it can be used directly after its production, thus avoiding an important part of production cost currently existing in the fabrication of conventional biodiesel.

Accordingly, the 1,3 selective behaviour of these free lipase, could open a new way to deal with the production of alternative biodiesel using an enzymatic approach, technically feasible and economically viable.

\section{Acknowledgments}

Grants from the Spanish Ministry of Economy and Competitiveness (Project ENE 2011-27017), Spanish Ministry of Education and Science (Projects CTQ2010-18126 and CTQ2011-28954-C02-02), FEDER funds and Junta de Andalucía FQM 0191, PO8-RMN-03515 and P11-TEP-7723 are gratefully acknowledged by the authors. We are also gratefully to Biocon®-Spain, for the kindly supply of the BIOLIPASE-R ${ }^{\circledR}$.

\section{Conflicts of Interest}

The authors declare no conflict of interest.

\section{References and Notes}

1. Demirbas, A. Political, economic and environmental impacts of biofuels: A review. Applied Energy 2009, 86, S108-S117.

2. Luque, R.; Herrero-Davila, L.; Campelo, J.M.; Clark, J.H.; Hidalgo, J.M.; Luna, D.; Marinas, J.M.; Romero, A.A. Biofuels: A technological perspective. Energy \& Environmental Science 2008, 1 .

3. Luna D., C.J., Sancho E.D., Luna C. , Posadillo A., Bautista F.M., Romero A.A., Berbel J., Verdugo C. Technological challenges for the production of biodiesel in arid lands. Journal of Arid Environments 2014, 102, 127-138.

4. Oh, P.P.; Lau, H.L.N.; Chen, J.H.; Chong, M.F.; Choo, Y.M. A review on conventional technologies and emerging process intensification (pi) methods for biodiesel production. Renewable \& Sustainable Energy Reviews 2012, 16, 5131-5145.

5. Saleh, J.; Dube, M.A.; Tremblay, A.Y. Separation of glycerol from fame using ceramic membranes. Fuel Processing Technology 2011, 92, 1305-1310. 
6. Ganesan D; Rajendran A; V, T. An overview on the recent advances in the transesterification of vegetable oils for biodiesel production using chemical and biocatalysts. Rev. Environ. Sci. Biotech 2009; pp 367-394.

7. Ilham, Z.; Saka, S. Two-step supercritical dimethyl carbonate method for biodiesel production from jatropha curcas oil. Bioresource Technology 2010, 101, 2735-2740.

8. Kim, S.J.; Jung, S.M.; Park, Y.C.; Park, K. Lipase catalyzed transesterification of soybean oil using ethyl acetate, an alternative acyl acceptor. Biotechnology and Bioprocess Engineering 2007, 12, 441-445.

9. Tan, K.T.; Lee, K.T.; Mohamed, A.R. Response to "Comment on a glycerol-free process to produce biodiesel by supercritical methyl acetate technology: An optimization study via response surface methodology". Bioresource Technology 2011, 102, 3990-3991.

10. Casas, A.; Ruiz, J.R.; Ramos, M.J.; Perez, A. Effects of triacetin on biodiesel quality. Energy \& Fuels 2010, 24, 4481-4489.

11. Caballero, V.; Bautista, F.M.; Campelo, J.M.; Luna, D.; Marinas, J.M.; Romero, A.A.; Hidalgo, J.M.; Luque, R.; Macario, A.; Giordano, G. Sustainable preparation of a novel glycerol-free biofuel by using pig pancreatic lipase: Partial 1,3-regiospecific alcoholysis of sunflower oil. Process Biochemistry 2009, 44, 334-342.

12. Verdugo, C.; Luna, D.; Posadillo, A.; Sancho, E.D.; Rodriguez, S.; Bautista, F.; Luque, R.; Marinas, J.M.; Romero, A.A. Production of a new second generation biodiesel with a low cost lipase derived from thermomyces lanuginosus: Optimization by response surface methodology. Catalysis Today 2011, 167.

13. Luna D; Bautista FM; Caballero V; Campelo JM; Marinas JM; AA., R. Method for producing biodiesel using porcine pancreatic lipase as an enzymatic catalyst. . European Patent EP 2050 823 A1; Bulletin 2009/17; 22.04.2009.

14. Luna, D.; Posadillo, A.; Caballero, V.; Verdugo, C.; Bautista, F.M.; Romero, A.A.; Sancho, E.D.; Luna, C.; Calero, J. New biofuel integrating glycerol into its composition through the use of covalent immobilized pig pancreatic lipase. International Journal of Molecular Sciences 2012, 13.

15. Luna, C.; Sancho, E.; Luna, D.; Caballero, V.; Calero, J.; Posadillo, A.; Verdugo, C.; Bautista, F.M.; Romero, A.A. Biofuel that keeps glycerol as monoglyceride by 1, 3-selective ethanolysis with pig pancreatic lipase covalently immobilized on alpo4 support. Energies 2013, 6, 38793900.

16. Wadumesthrige, K.; Ara, M.; Salley, S.O.; Ng, K.Y.S. Investigation of lubricity characteristics of biodiesel in petroleum and synthetic fuel. Energy \& Fuels 2009, 23, 2229-2234.

17. Xu, Y.F.; Wang, Q.J.; Hu, X.G.; Li, C.; Zhu, X.F. Characterization of the lubricity of biooil/diesel fuel blends by high frequency reciprocating test rig. Energy 2010, 35, 283-287.

18. Haseeb, A.; Sia, S.Y.; Fazal, M.A.; Masjuki, H.H. Effect of temperature on tribological properties of palm biodiesel. Energy 2010, 35, 1460-1464.

19. Çelikten, I. The effect of biodiesel, ethanol and diesel fuel blends on the performance and exhaust emissions in a di diesel engine. Gazi Univ J Sci 2011; pp 341-346.

20. Cheenkachorn, K.; Fungtammasan, B. Biodiesel as an additive for diesohol. International Journal of Green Energy 2009, 6, 57-72.

21. Jaganjac, M.; Prah, I.O.; Cipak, A.; Cindric, M.; Mrakovcic, L.; Tatzber, F.; Ilincic, P.; Rukavina, V.; Spehar, B.; Vukovic, J.P., et al. Effects of bioreactive acrolein from automotive exhaust gases on human cells in vitro. Environmental Toxicology 2012, 27, 644-652.

22. Pang, X.B.; Mu, Y.J.; Yuan, J.; He, H. Carbonyls emission from ethanol-blended gasoline and biodiesel-ethanol-diesel used in engines. Atmospheric Environment 2008, 42, 1349-1358.

23. Szczesna-Antczak, M.; Kubiak, A.; Antczak, T.; Bielecki, S. Enzymatic biodiesel synthesis key factors affecting efficiency of the process. Renewable Energy 2009, 34, 1185-1194.

24. Moayedallaie, S.; Mirzaei, M.; Paterson, J. Bread improvers: Comparison of a range of lipases with a traditional emulsifier. Food Chemistry 2010, 122, 495-499. 
25. Yara-Varon, E.; Joli, J.E.; Torres, M.; Sala, N.; Villorbina, G.; Mendez, J.J.; Canela-Garayoa, R. Solvent-free biocatalytic interesterification of acrylate derivatives. Catalysis Today 2012, 196, 86-90.

26. Chang, C.; Chen, J.H.; Chang, C.M.J.; Wu, T.T.; Shieh, C.J. Optimization of lipase-catalyzed biodiesel by isopropanolysis in a continuous packed-bed reactor using response surface methodology. New Biotechnology 2009, 26, 187-192.

(C) 2014 by the authors; licensee MDPI, Basel, Switzerland. This article is an open access article distributed under the terms and conditions of the Creative Commons Attribution license (http://creativecommons.org/licenses/by/3.0/). 